\title{
ИМПОРТ АЛКОГОЛЬНЫХ ПОДАКЦИЗНЫХ ТОВАРОВ В РФ
}

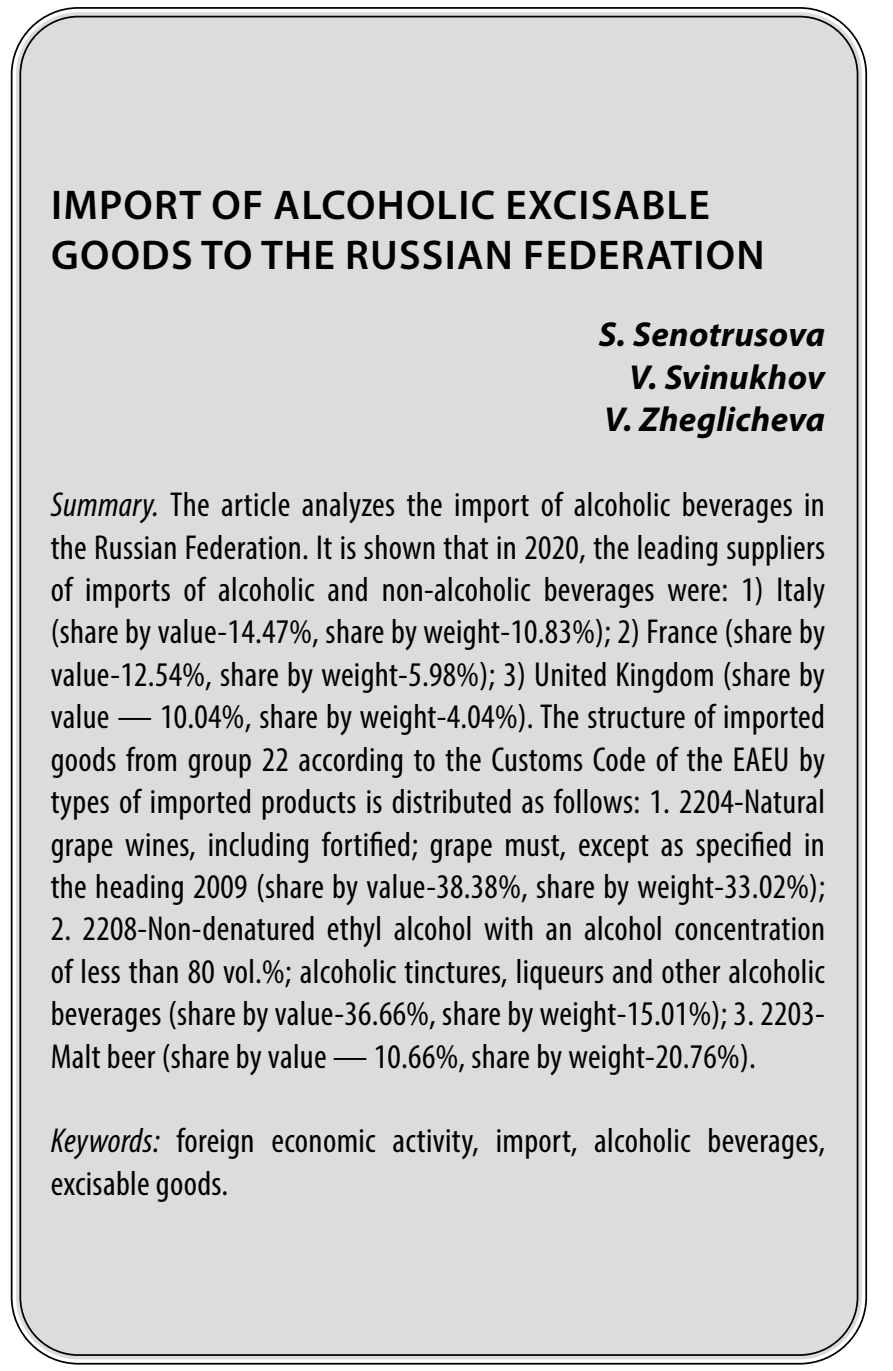

Summary. The article analyzes the import of alcoholic beverages in the Russian Federation. It is shown that in 2020, the leading suppliers of imports of alcoholic and non-alcoholic beverages were: 1) Italy (share by value-14.47\%, share by weight-10.83\%); 2) France (share by value-12.54\%, share by weight-5.98\%); 3) United Kingdom (share by value $-10.04 \%$, share by weight- $4.04 \%$ ). The structure of imported goods from group 22 according to the Customs Code of the EAEU by types of imported products is distributed as follows: 1. 2204-Natural grape wines, including fortified; grape must, except as specified in the heading 2009 (share by value- $38.38 \%$, share by weight-33.02\%) 2. 2208-Non-denatured ethyl alcohol with an alcohol concentration fless than 80 vol.\%; beverages (share by value-36.66\%, share by weight-15.01\%); 3.2203 -

Keywords: foreign economic activity, import, alcoholic beverages, excisable goods.

\author{
Сенотрусова Светлана Валентиновна \\ Д.б.н., профессор, Московский государственный \\ университет им. М.В. Ломоносова \\ svetlsen@mail.ru \\ Свинухов Владимир Геннадьевич \\ Д.2.н., профессор, Российский экономический \\ университет имени Г.В. Плеханова \\ customs_fgu@mail.ru \\ Жегличева Вероника Владимировна \\ Преподаватель, Российский экономический \\ университет имени Г.В. Плеханова \\ inmar2000@mail.ru
}

Аннотация. В статье проанализирован импорт товаров алкогольной продукции в РФ. Показано, что в 2020 году ведущими поставщиками импорта алкогольных и безалкогольных напитков выступили: 1) Италия (доля по стоимости - 14,47\%, доля по массе - 10,83\%); 2) Франция (доля по стоимости - 12,54\%, доля по массе - 5,98\%); 3) Соединенное Королевство (доля по стоимости - 10,04\%, доля по массе - 4,04\%). Структура ввозимых товаров из группы 22 по ТН ВэД ЕАЭС по видам импортной продукции распределяется следующим образом: 1. 2204 - Вина виноградные натуральные, включая крепленые; сусло виноградное, кроме указанного в товарной позиции 2009 (доля по стоимости - 38,38\%, доля по массе - 33,02\%);

2. 2208 - Спирт этиловый неденатурированный с концентрацией спирта менее 80 0б.\%; спиртовые настойки, ликеры и прочие спиртные напитки (доля по стоимости - 36,66\%, доля по массе - 15,01\%); 3. 2203 - Пиво солодовое (доля по стоимости - 10,66\%, доля по массе - 20,76\%).

Ключевые слова: внешнеэкономическая деятельность, импорт, алкогольная продукция, подакцизные товары.

рой подлежит обложению акцизным сбором. В частности, к подакцизной алкогольной продукции относятся: водка; ликероводочные изделия; коньяки; вино (в том числе фруктовое, ликерное, игристое), винные напитки; сидр; пуаре; медовуха; пиво, пивные напитки.

Для расчета акциза на алкогольную продукцию используются твердые ставки, установленные в рублях:

- на литр готовой продукции (для пива, вин, сидра, пуаре, медовухи);

- на литр безводного этилового спирта, содержащегося в товаре (для прочей алкогольной продукции).

В отличие от табачных изделий, акциз на спирт и алкогольную продукцию в 2021 году повышен не был. Ниже в таблице 2 представлена актуальная инфор- 
Таблица 1. Ставки ввозных пошлин на товары группы 22 ТН ВЭД ЕАЭС [3]

\begin{tabular}{|c|c|c|c|c|c|}
\hline Наименование & Емкость & Код товара & Пошлина & НдС & Акциз \\
\hline \multirow{3}{*}{ Пиво солодовое } & \multirow{2}{*}{ До 10 литров } & $\begin{array}{l}2203000100- \\
\text { в бутылках }\end{array}$ & \multirow{2}{*}{ 0,018 евро/л } & \multirow{2}{*}{$20 \%$} & \multirow{2}{*}{$\begin{array}{l}39 \text { руб./л или } \\
21 \text { руб./л }\end{array}$} \\
\hline & & $\begin{array}{l}2203000900- \\
\text { прочее }\end{array}$ & & & \\
\hline & Более 10 л & 2203001000 & 0,04 евро/л & $20 \%$ & \begin{tabular}{|l}
39 руб./л или \\
21 руб./л
\end{tabular} \\
\hline Сусло виноградное & - & 2204301000 & $5 \%$ & $20 \%$ & $\begin{array}{l}\text { Без акциза или } \\
418 \text { руб./л или } \\
523 \text { руб./л сп. }\end{array}$ \\
\hline $\begin{array}{l}\text { Крепкие алкогольные напитки типа } \\
\text { коньяка, виски }\end{array}$ & - & $\begin{array}{l}2208201200 \text { - для } \\
\text { коньяка, } \\
2208301100 \text { - для } \\
\text { виски «бурбон» }\end{array}$ & 1,5 евро/л & $20 \%$ & $\begin{array}{l}523 \text { руб./ л сп. } \\
\text { или } 418 \text { руб./л } \\
\text { сп. }\end{array}$ \\
\hline Очищенный этиловый спирт & - & 2207100000 & $\begin{array}{l}\text { 100\% или } 2 \\
\text { евро/л }\end{array}$ & $20 \%$ & 107 руб./ л сп. \\
\hline
\end{tabular}

Таблица 2. Ставки акциза на товары группы 22 ТН ВЭД ЕАЭС [4]

\begin{tabular}{|c|c|}
\hline Наименование подакцизного товара & Ставка акцизного сбора в 2021 году \\
\hline $\begin{array}{l}\text { Алкогольная продукция с объемной долей этилового спирта } \\
\text { свыше 9\% }\end{array}$ & $\begin{array}{l}523 \text { руб./1 л безводного этилового спирта, содержащегося } \\
\text { в товаре }\end{array}$ \\
\hline $\begin{array}{l}\text { Алкогольная продукция с объемной долей этилового спирта } \\
\text { до 9\% }\end{array}$ & $\begin{array}{l}418 \text { руб./1 л безводного этилового спирта, содержащегося } \\
\text { в товаре }\end{array}$ \\
\hline Вина & 18 руб./1 л \\
\hline $\begin{array}{l}\text { Вина с защищенным географическим указанием, } \\
\text { с защищенным наименованием места происхождения, } \\
\text { за исключением игристых вин (шампанских) }\end{array}$ & 5 руб./1 л \\
\hline Пуаре, медовуха, сидр & 21 руб./1 л \\
\hline Игристые (шампанские) вина & 36 руб./1 л \\
\hline $\begin{array}{l}\text { Игристые вина (шампанские) с защищенным географическим } \\
\text { указанием, с защищенным наименованием места } \\
\text { происхождения }\end{array}$ & 14 руб./1 л \\
\hline Пиво с содержанием этилового спирта от 0,5\% до 8,6\% & 21 руб./1 л \\
\hline Пиво с содержанием этилового спирта свыше 8,6\% & 39 руб./1 л \\
\hline
\end{tabular}

мация по ставкам акциза на алкогольную продукцию в 2021 году.

Расчет акциза на алкогольную продукцию производится по формуле:

Акциз $_{\text {алкогольная продукция }}=$ Ставка $*$ Объем Прод (1),

где Ставка - ставка, установленная НК РФ для каждого вида алкогольной продукции; ОбъемПрод -объем содержания этилового спирта, содержащегося в алкогольном товаре либо объем продукции.

Анализ статистических данных международной торговли показал, что импорт в Россию товаров из группы «напитки алкогольные и безалкогольные» за период 2016-2020 составил \$7.54 млрд., общим весом 4690 тыс. тонн. В основном импортировались «вина виноградные, натуральные» (40\%), «спирт этиловый с концентрацией менее 80\%» (37\%).

В 2020 году общий стоимостной объем импорта составил 3,02 млрд. \$ при массе груза 1,99 млн. тонн. Анализ месячной динамики показывает, что поставки товара в течение года нарастают и максимум поставок приходится на ноябрь 2020 г., а минимум - на январь 2020 г. Отметим, что фактически поставки товара в декабре удваиваются относительно января (табл. 3). При этом стоимость единицы товара возрастает.

Ведущими поставщиками импорта алкогольных и безалкогольных напитков выступили: 1) Италия (доля по стоимости - 14,47\%, доля по массе - 10,83\%); 2) Франция (доля по стоимости - 12,54\%, доля по мас- 
Таблица 3. Динамика импорта товаров группы 22 ТН ВЭД ЕАЭС за 2020 год [5]

\begin{tabular}{|l|l|l|l|}
\hline Период & Стоимость, \$ & Масса, тонн & стоимость 1 литра, \$ \\
\hline $2020-01$ & 155,68 млн. & 100,4 тыс. & 1,55 \\
\hline $2020-02$ & 209,68 млн. & 138,41 тыс. & 1,51 \\
\hline $2020-03$ & 208,72 млн. & 146,19 тыс. & 1,42 \\
\hline $2020-04$ & 221,85 млн. & 168,54 тыс. & 1,34 \\
\hline $2020-05$ & 215,43 млн. & 168,26 тыс. & 1,28 \\
\hline $2020-06$ & 223,14 млн. & 172,97 тыс. & 1,20 \\
\hline $2020-07$ & 261,63 млн. & 179,91 тыс. & 1,46 \\
\hline $2020-08$ & 245 млн. & 164,9 тыс. & 1,48 \\
\hline $2020-09$ & 270,41 млн. & 170,34 тыс. & 1,58 \\
\hline $2020-10$ & 315,85 млн. & 184,45 тыс. & 1,71 \\
\hline $2020-11$ & 348,04 млн. & 195 тыс. & 1,78 \\
\hline $2020-12$ & 346,54 млн. & 200,52 тыс. & 1,77 \\
\hline
\end{tabular}

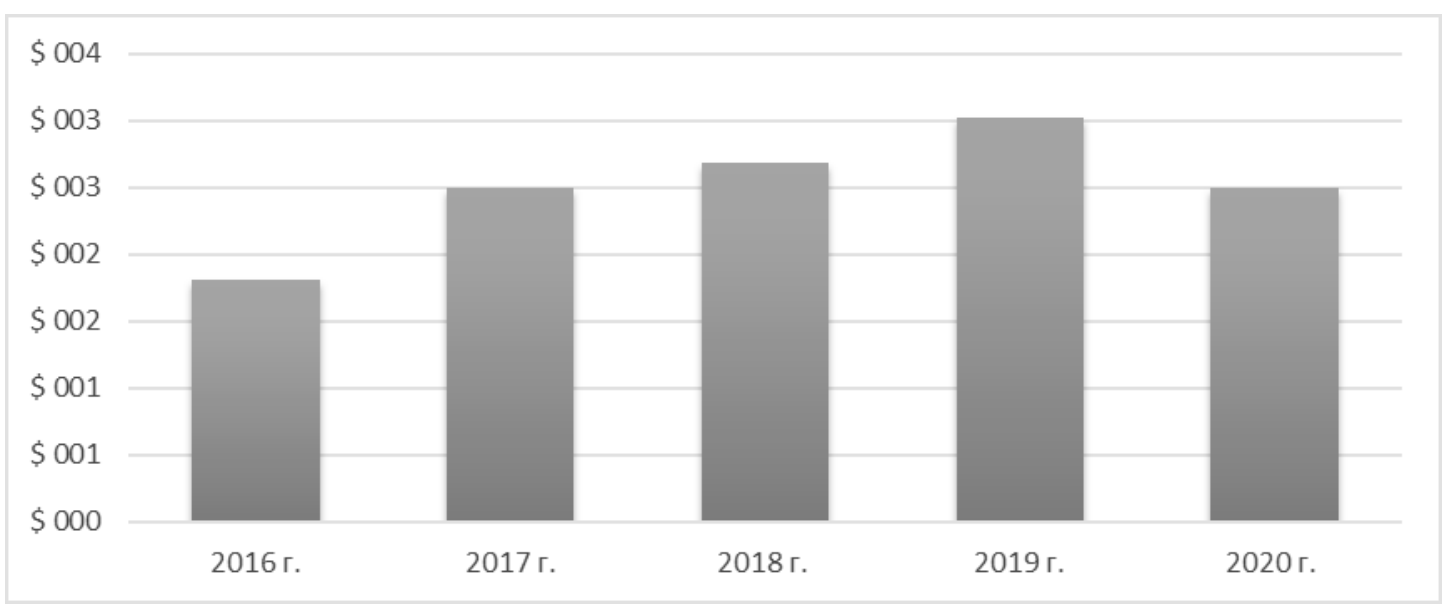

Рис. 1. Импорт товаров группы 22 ТН ВЭД ЕАЭС в Россию в 2016-2020 гг., в долл.

се - 5,98\%); 3) Соединенное Королевство (доля по стоимости - 10,04\%, доля по массе - 4,04\%). Четвертое место занимает Грузия (доля по стоимости - 8,2\%, доля по массе - 12,0\%). На пятом месте располагается Армения (доля по стоимости - 8,07\%, доля по массе 5,64\%) (табл. 4).

Стоимость единицы товара изменяется в широких пределах от 0,44 \$ за 1 литр (Беларусь) до 4,2 \$ за 1 литр (США). Однако для ведущих мировых экспортеров стоимость одного литра варьируется от 2,2 \$ за 1 (Италия) литр до 3,7 \$ за 1 литр (Великобритания).

В таблице 5 представлена структура ввозимых товаров из группы 22 по ТН ВЭД ЕАЭС по видам продукции.
1. 2204-Вина виноградные натуральные, включая крепленые; сусло виноградное, кроме указанного в товарной позиции 2009 (доля по стоимости - 38,38\%, доля по массе - 33,02\%);

2. 2208 - Спирт этиловый неденатурированный с концентрацией спирта менее 80 об.\%; спиртовые настойки, ликеры и прочие спиртные напитки (доля по стоимости - 36,66\%, доля по масce $-15,01 \%)$;

3. 2203 - Пиво солодовое (доля по стоимости $10,66 \%$, доля по массе - 20,76\%)

Импорт в Россию товаров товарных позиций 2202 ТН ВЭД - Воды, включая минеральные и газированные..., 2206 - Прочие напитки сброженные (сидр 
Таблица 4. Страны - ведущие поставщики товаров группы 22 ТН ВЭД ЕАЭС за 2020 год

\begin{tabular}{|c|c|c|c|c|c|}
\hline Страна & Стоимость & Macca & $\begin{array}{l}\text { стоимость } 1 \\
\text { литра, \$ }\end{array}$ & Доля по стоимости & Доля по массе \\
\hline Италия & 437,31 млн. \$ & 215,59 тыс. тонн & 2,02 & $14,47 \%$ & $10,83 \%$ \\
\hline Франция & 378,95 млн. \$ & 119,01 тыс. тонн & 3,18 & $12,54 \%$ & $5,98 \%$ \\
\hline $\begin{array}{l}\text { Соединенное } \\
\text { Королевство }\end{array}$ & 303,35 млн. \$ & 80,3 тыс. тонн & 3,77 & $10,04 \%$ & $4,04 \%$ \\
\hline Грузия & 250,09 млн. \$ & 238,88 тыс. тонн & 1,04 & $8,28 \%$ & $12,00 \%$ \\
\hline Армения & 243,94 млн. \$ & 112,18 тыс. тонн & 2,17 & $8,07 \%$ & $5,64 \%$ \\
\hline Испания & 222,03 млн. \$ & 170,45 тыс. тонн & 1,30 & $7,35 \%$ & $8,57 \%$ \\
\hline Германия & 190,17 млн. \$ & 194,76 тыс. тонн & 0,97 & $6,29 \%$ & $9,79 \%$ \\
\hline Соединенные Штаты & 92,57 млн. \$ & 21,53 тыс. тонн & 4,2 & $3,06 \%$ & $1,08 \%$ \\
\hline Ирландия & 80,81 млн. \$ & 21,58 тыс. тонн & 3,74 & $2,67 \%$ & $1,08 \%$ \\
\hline Беларусь & 69,41 млн. \$ & 156,98 тыс. тонн & 0,44 & $2,30 \%$ & $7,89 \%$ \\
\hline Мексика & 58,94 млн. \$ & 35,02 тыс. тонн & 1,68 & $1,95 \%$ & $1,76 \%$ \\
\hline Абхазия & 57,18 млн. \$ & 37,72 тыс. тонн & 1,51 & $1,89 \%$ & $1,90 \%$ \\
\hline Литва & 55,08 млн. \$ & 70,09 тыс. тонн & 0,78 & $1,82 \%$ & $3,52 \%$ \\
\hline Бельгия & 47,75 млн. \$ & 39,23 тыс. тонн & 1,21 & $1,58 \%$ & $1,97 \%$ \\
\hline Чили & 45,17 млн. \$ & 25,19 тыс. тонн & 1,79 & $1,49 \%$ & $1,27 \%$ \\
\hline Чешская Республика & 43,17 млн. \$ & 51,8 тыс. тонн & 0,83 & $1,43 \%$ & $2,60 \%$ \\
\hline Корея & 35,91 млн. \$ & 48,93 тыс. тонн & 0,73 & $1,19 \%$ & $2,46 \%$ \\
\hline Австрия & 32,82 млн. \$ & 30,17 тыс. тонн & 1,08 & $1,09 \%$ & $1,52 \%$ \\
\hline Нидерланды & 32,15 млн. \$ & 27,09 тыс. тонн & 1,18 & $1,06 \%$ & $1,36 \%$ \\
\hline Португалия & 29,44 млн. \$ & 16,1 тыс. тонн & 1,82 & $0,97 \%$ & $0,81 \%$ \\
\hline Остальные 116 стран & 315,74 млн. \$ & 277,28 тыс. тонн & 1,13 & $10,45 \%$ & $13,93 \%$ \\
\hline
\end{tabular}

Таблица 5. Структура ввозимых товаров из группы 22 по ТН ВЭД ЕАЭС по видам продукции за 2020 год

\begin{tabular}{|c|c|c|c|c|}
\hline ТНВЭД & Стоимость & Macca & $\begin{array}{l}\text { Доля } \\
\text { по стоимости }\end{array}$ & $\begin{array}{l}\text { Доля } \\
\text { по массе }\end{array}$ \\
\hline $\begin{array}{l}2204 \text { - Вина виноградные натуральные, } \\
\text { включая кр... }\end{array}$ & 1,16 млрд. \$ & 657,09 тыс. тонн & $38,38 \%$ & $33,02 \%$ \\
\hline $\begin{array}{l}2208 \text { - Спирт этиловый } \\
\text { неденатурированный с конц... }\end{array}$ & 1,11 млрд. \$ & 298,6 тыс. тонн & $36,66 \%$ & $15,01 \%$ \\
\hline 2203 - Пиво солодовое & 322,12 млн. \$ & 413,06 тыс. тонн & $10,66 \%$ & $20,76 \%$ \\
\hline $\begin{array}{l}2202 \text { - Воды, включая минеральные } \\
\text { и газированные... }\end{array}$ & 205,75 млн. \$ & 286,8 тыс. тонн & $6,81 \%$ & $14,41 \%$ \\
\hline $\begin{array}{l}2201 \text { - Воды, включая природные или } \\
\text { искусственны... }\end{array}$ & 115,47 млн. \$ & 226,58 тыс. тонн & $3,82 \%$ & $11,39 \%$ \\
\hline $\begin{array}{l}2206 \text { - Прочие напитки сброженные (сидр } \\
\text { яблочный... }\end{array}$ & 68,92 млн. \$ & 75,77 тыс. тонн & $2,28 \%$ & $3,81 \%$ \\
\hline $\begin{array}{l}2205 \text { - Вермуты и виноградные натуральные } \\
\text { вина п... }\end{array}$ & 33,94 млн. \$ & 21,63 тыс. тонн & $1,12 \%$ & $1,09 \%$ \\
\hline $\begin{array}{l}2209 \text { - Уксус и его заменители, полученные } \\
\text { из ук... }\end{array}$ & 7,47 млн. \$ & 10,05 тыс. тонн & $0,25 \%$ & $0,51 \%$ \\
\hline $\begin{array}{l}2207 \text { - Спирт этиловый } \\
\text { неденатурированный с конц... }\end{array}$ & 557,59 тыс. \$ & 296,18 тонн & $0,02 \%$ & $0,01 \%$ \\
\hline
\end{tabular}


яблочный...), 2205 - Вермуты и виноградные натуральные вина ... и других составляет в 2020 году около 400 млн. \$.

Рынок алкогольной и безалкогольной продукции в РФ уже на протяжении многих лет имеет высокую важность, как с позиции экономической составляющей, так и с позиции социальной сферы. Наибольшая доля спиртосодержащей и безалкогольной продукции, производимой в РФ и ввозимой из-за границы, представляется подакцизной, вследствие чего дает возможность государству пополнять государственный бюджет.

\section{ЛИТЕРАТУРА}

1. Баландина Г. Таможенно-тарифная политика и стимулирование инноваций в России. / Г. Баландина, Н. Воловик, С. Приходько. - М.: Издательский дом Дело РАНХиГС, 2018. - 228 с.

2. Немирова Г.И. Таможенные платежи как фактор развития экономического потенциала России. / Г.И. Немирова, 3.А. Ильсаев. // Экономика и социум. - № 3. - 2020.- С. 29-33.

3. Иванова В.Ю. Таможенные пошлины во внешнеторговой деятельности. / В.Ю. Иванова. // Вестник Сибирского федерального университета. — № 3. 2018. - С. 11-13.

4. Налоговый кодекс Российской Федерации (часть первая) от 31.07.1998 N146-Ф3 (ред. от 29.09.2019, с изм. от 31.10.2019) (с изм. и доп., Вступ. В силу с 29.10.2019) // КонсультантПлюс: справочно-правовая система [0фиц. сайт]. URL: http://www.consultant.ru/.

5. Савинова Е.А. Статистический анализ объёмов и структуры таможенных платежей в РФ. / Е.А. Савинова, В.Г. Степченко. // Экономика и современный менеджмент.— № 7.— 2017.- С. 41-45.

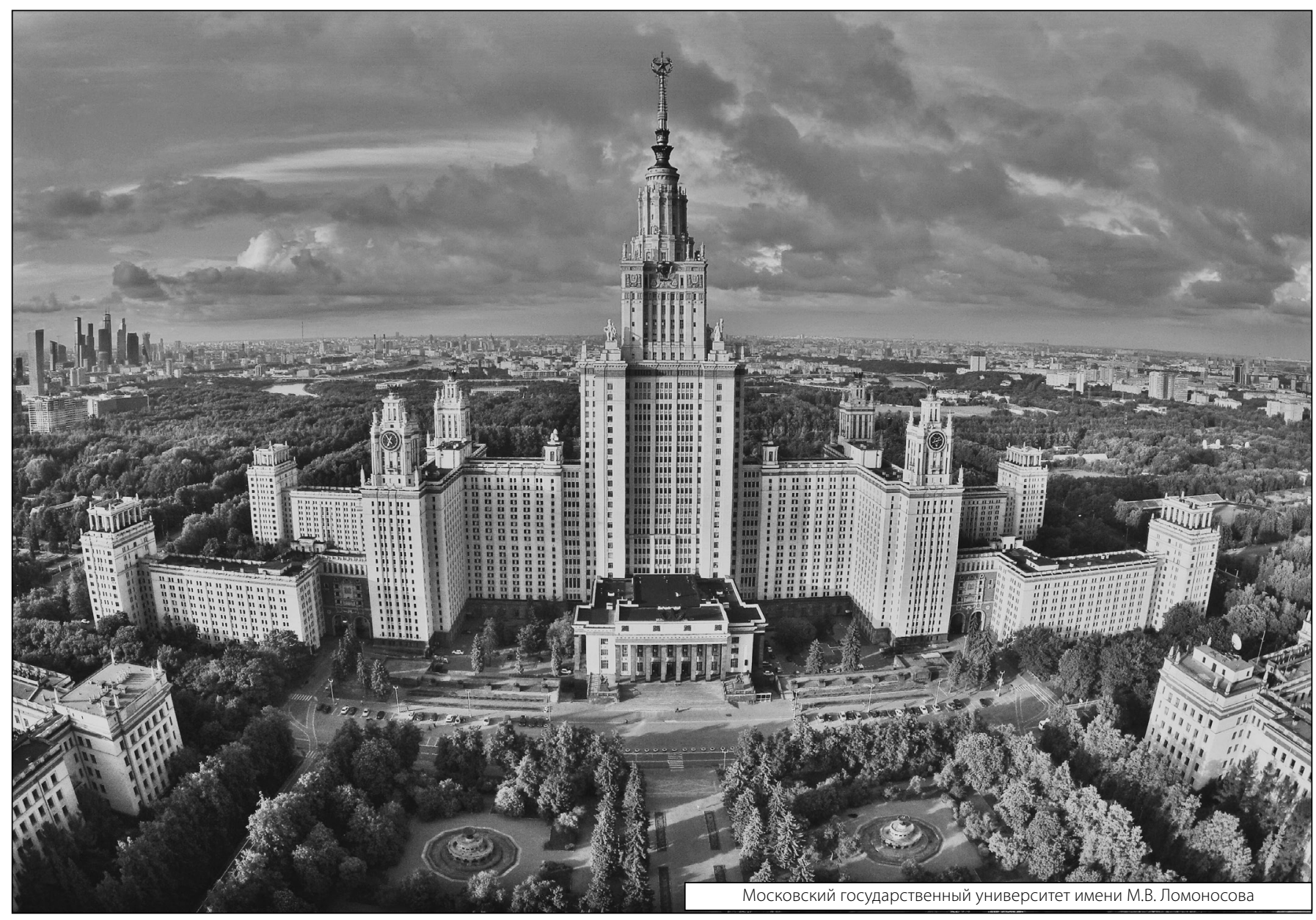

